\title{
Promoting Local Economy Development with Integration of Culture and Tourism
}

\author{
Shuhui Ren \\ Business School, Xi'an International University, Xi'an, 710077, China
}

Keywords: Culture, Tourism, Integration, Local Economy

\begin{abstract}
The local economy development is badly in need of the support of culture and tourism. Culture is considered as the soul of tourism, so only the tourism resources with culture can be equipped with lasting charm. However, tourism is the important foundation of cultural development, which is able to promote the development of cultural industry. Cultural tourism industry which combines culture and tourism will inevitably better explore local culture, strengthen local tourism, and promote the local economy adjustment and economic transition. Therefore, integration of culture and tourism has become the vital direction of local economy transition and development. This paper analyzes the relationship between culture and tourism, lists the promoting effects of integration of culture and tourism on local economy development, and puts forward local economy developing strategy in view of integration of culture and tourism.
\end{abstract}

\section{Introduction}

Nowadays, culture has become the inner soul of tourism, keeping close connection and integration with tourism. No matter for leisure tourism or creative tourism, the similarity is that travelers pay high attention to cultural enjoyment and pursuit. Tourism takes colorful tourism resources as main contents and good-quality tourist facilities as dependence in order to practically meet all kinds of tourist consumption requirement on basis of carrying out tourism service. Chinese nation has five thousand years of civilization history and splendid culture. Most areas have significant cultural resources worthy of trust and inheritance, becoming a vital support for current tourism. On basis of the sustainable development of China tourism, comprehensive integration of tourism and economy, and culture and ecology has been realized, generating comprehensive and systematic modern new-type tourism culture. It needs to take tourism as guidance, practically improve the integration of culture and tourism, and promote the comprehensive development of local economy.

\section{Relationship between culture and tourism}

\section{Tourism and culture have intrinsic relationship.}

There is certain relationship between tourism and culture. Tourism can be considered as a significant essential characteristic of modern people's civilization activity. In a broad sense, culture refers to the combination of material wealth and spiritual wealth created by modern people, which is rightly the essential difference between human beings and animals. Human beings can only have in-depth and lasting development in mental or emotional aspect after having corresponding material satisfaction, so that good culture value can be created. In a narrow sense, culture means spiritual one which is also the inner requirement of culture. That is to say, modern tourism takes the way of exploiting living space, tries every means to promote spiritual development, and improve them with culture. The external manifestation of tourism mainly means communication of tourism culture which is also a vital way to promote modern people' s development. Real tourism as a kind of thirsty for knowledge and aesthetic appreciation is able to better expand modern people' $s$ horizon, fully improve their living condition, and promote their spiritual pursuit.

\section{Culture is the inner soul of tourism}

Nowadays, tourism has become the biggest emerging industry in the world because the emergence and development of tourism keep close relationship with culture all the way. Tourism as a 
kind of economic industry on basis of culture takes culture as its essential carrier. Tourism resources are mainly divided into natural landscape and human landscape with the latter one meaning all kinds of materials created by culture. The main contents are significant cultural characteristics. Tourism mainly attracts travelers with unique culture of a certain country or region and then gets good economic benefit. That is to say, tourism economy belongs to a kind of activity which combines culture and economy together closely. It uses reasonable cultural concept and spiritual need to practically meet travelers’ ornamental demand especially all kinds of spiritual and cultural needs.

\section{Promotion effects of integration of culture and tourism on local economy development}

Integration of culture and tourism can promote the great development of local tourism.

As modern people's consumption view, consumption ability and consumption level rise, tourist consumption has already become rigid expense of most travelers. During the golden week in 2015, the tourist income of all country has reached 290 billion Yuan with per capita tourism expenditure more than 600 Yuan. For the reason that modern people pay more and more attention to cultural consumption, tourism's economic benefits rely on cultural tourism products, facilities and service. For example, Yunnan Province mainly relies on its good reputation of flora and fauna kingdom and national culture center, using strong tourism culture characteristics to guide regional tourism development. However, Guangdong, a province with famous tourism culture, leads our country in aspects like inbound traveler reception, tourism income, etc.

\section{Integration of culture and tourism can promote the transition and upgrade of industrial structure in local economy.}

The integration of culture and tourism can realize highly blending of tourism and first-class, second-class, and third-class industry, generating brand-new tourism products and brands, and promoting adjustment and upgrade of industrial structure of our country. Each region should take its own economic development advantage as basis, and promote the further blending of industry, agriculture, service industry and tourism. Only in this way can more colorful cultural tourism products like industry tourism, agriculture tourism, service tourism, etc be created at macroscopic level, and more brand-new cultural tourism products with outstanding characteristics like car tourism, ecology tourism, financial tourism, etc be formed at microcosmic level. As the cultural tourism reputation of our country constantly improves, very strong aggregation effects can be generated. For example, in recent years Shanghai aims to put forward new-type tourism culture centered by business tourism, sports tourism and industrial tourism. Shanghai also creates series of new tourism products especially the products must be bought and eaten in Shanghai. Therefore, it plays a vital role in gathering all kinds of tourism production elements and developing modern industry groups.

Integration of culture and tourism can promote the financial strength in local economy.

With the rapid development of modern scientific and technological information especially new media, the speed of cultural transmission becomes faster and faster. As a result, conduction becomes a rather necessary character in modern tourism culture and also the significant driving force of tourism culture to promote local economy development. Tourism which takes tourism culture with characteristics and favorable connotation as main driving force is equipped with so strong advantage that it has more and more irresistible attraction for travelers. For example, many cities like Hangzhou, Nanjing, Sanya, Suzhou, Lijiang, Guilin, Zhangjiajie, Huangshan, Xiamen, etc become modern people's first tourism choice because of their integration charm of unique culture and tourism, which greatly improves the financial income of these cities. It provides significant support for improvement of local financial power.

Integration of culture and tourism can promote the popularity effect of local economy.

Culture is equipped with very important transmissibility and popularity. The tourism culture with unique characteristics is actually an essential signboard for a country, a district, a city and even a village, generating great propagative power. In this way, the effects of improving popularity published to the public can be fully embodied. In fact, such kind of examples can be found everywhere. Without the unique Confucian culture connotation of the Kong Family Mansion, Tai'an Shandong cannot be known by so many people; without state office tourism culture, Neixiang Henan 
cannot win great reputation; without old-style bank tourism culture, Pingyao Shanxi is not able to attract more and more tourist consumers. Culture name card effect which constantly appears in local economy is able to attract more tourists, promote contemporary economic prosperity, expand commercial trade communication, strengthen cooperation between regions or countries, generate powerful tourism alliance, and facilitate the favorable cyclic development of local economy.

\section{Local economy development strategy in integrated view of culture and tourism}

\section{Strengthening ideological and political education promotes the comprehensive integration and development of culture and tourism.}

Ideological and political education can be considered as the starting point of all jobs. Actively strengthening ideological and political education is able to promote the comprehensive integration and development of culture and tourism. With help of the omnibearing and multi-angle integrated development of culture and tourism, a completely harmonious and equal relationship will appear between them. The mutual integration and improvement between culture and tourism will exert favorable economic and social benefit. However, it can be seen from current developing trend that compared with current increasing market requirement and richer and richer cultural tourism advantages, the current situation of culture tourism still has various problems like narrow cooperation scope, blocked cooperation system, inadequate policy support for the development of culture and tourism, etc. Therefore, we should practically strengthen the integrated development of culture and tourism, reinforce ideological and political education, and change the stale idea of merely emphasizing tourist culture element, so that we may promote the integration at depth and breadth level and form a brand-new win-win way of tourism and culture industry. Mutual integration should be taken as driving force to practically form a favorable environment for the integration development of culture and tourism. At present, Chinese cultural tourism has entered a critical period of comprehensive integration and upgrade, which needs to place the development of tourism into local overall planning and form a new development view named "a city is tourism, tourism is a city". In addition, tourism destination construction should also be taken as basis to realize synchronous planning and arrangement of tourism and city construction. The market subject cultivation should be actively strengthened to encourage all kinds of social capital into cultural tourism. Finally the integration management mechanism of culture and tourism should be carried out to reinforce the integrity mechanism construction of culture and tourism, better exert great attraction of industrial associations, and form a new situation of integrated development of culture and tourism.

\section{Strengthening cultural connotation construction promotes the transformation and upgrade of characteristic tourism.}

Chinese culture has rich connotation. Tourism without cultural connotation must be lack of powerful vitality. The richer cultural connotation modern tourism products have, the more travelers can be attracted and the more powerful vitality and infection can be acquired. Therefore, the local special cultural charm should be used to develop characteristic tourism products, and cultural elements should also be used to improve the comprehensive service ability of tourism areas. That is to say, tourism is a strong industrial system with all elements like eating, living, and transportation. On basis of tourism function facilities, fashion culture should be carried out so that all kinds of entertainment projects can be developed more reasonably. Culture and modern technology should be combined with tourism industry, and all kinds of technology way should be actively used to promote transformation and upgrade of characteristic tourism. Only in this way can travelers enjoy their living and traveling there.

\section{Creating a new harmonious development situation of culture and tourism on basis of idea innovation.}

We should actively promote the harmonious development of culture and tourism industry, take reform and innovation as a significant driving force for cultural tourism development, and carry out innovation in form, content and carrier aspects.; we should improve the diversified and systematic development of Chinese tourism products, making cultural creative industry the real guidance; we should break the traditional boundary of cultural tourism industry, pay attention to the comprehensive 
integration and permeation of tourism, primary industry, secondary industry, and tertiary industry, and form recombination of different industries and regions by overstepping the boundary; We should combine with agriculture and develop manor tourism; we should integrate with industry, reasonably develop modern industrial tourism with characteristics like visiting, interview, and self-service, and make travelers understand industrial products' characteristics and manufacture process. For example, favorable environment renovation can be carried out for abandoned industrial mine lots, and then mine lot industrial tourism can be developed. Therefore, travelers can understand how the coal is formed, and realize coal workers' hardship. Moreover, entrepreneurs of coal industry will also be motivated to visit the old haunt and review the glory days of entrepreneurship. The powerful resources of modern industrial park can be used to develop modern industry tourism which faces college students with their study and career as main contents, faces investors with their attract investment as main contents, faces government and business units with investigation and survey as main contents, and faces the old with reminiscence as main contents. On this basis, original tourism products like craft innovation tourism, industrial environmental protection tourism, and industrial marketing tourism can be explored. In addition, the mutual connection of various elements and integration of related industries should be used to better promote local economy development.

\section{References}

[1] Xie Yaping, Liao Yonghong. Regional tourism resource and western Hubei eco-culture tourism circle construction-taking Xingshan County and Badong County in Hubei Province as example. Journal of China Three Gorges University (Humanity and Social Science Edition), 2010(2).

[2] Lei Qing. The promotion effects of tourism on economy in underdeveloped areas-taking Southern Shaanxi as example. China Business \& Trade, 2011(23).

[3] Shi Xianli. Research on the tourist economy benefit of cultural and creative products-taking “Impression • Third Sister Liu”. Modern Corporation Culture, 2012(3).

[4] Li Xiang. Analysis on the promotion effects of tourism development on Conghua economy. Success (Education), 2012(16).

[5] Li Jie. Analysis on economic influence of rural tourism development in Huangpi District. Journal of Central China Normal University, 2013(2) .

[6] Yang Ali, Yuan Xiaoliang. A restricted view on ecological civilization outlook under post-modern tourism theory. Journal of Anhui Agricultural University (Social Science Edition), 2014(3). 